This is the final draft, after peer-review, of a manuscript to be published in Medical Education (accepted for publication 05/06/2018). The definitive version will be available online at https://onlinelibrary.wiley.com/journal/13652923 (Article ID: MEDU13657; Article DOI: $10.1111 /$ medu.13657)

\title{
TITLE: What can Discrete Choice Experiments do for you?
}

\section{STRUCTURED ABSTRACT}

\section{Context}

In everyday life, the choices we make are influenced by our preferences for the alternatives available to us. The same is true when choosing medical education, training and jobs. More often than not, those alternatives comprise multiple attributes and our ultimate choice will be guided by the value we place on each attribute relative to the others. In education for example, choice of university is likely to be influenced by preferences for institutional reputation, location, cost and course content; but which of these attributes is the most influential? An understanding of what is valued by applicants, students, trainees and colleagues is of increasing importance in the higher education and medical job market places, in order to develop options that meet their needs and preferences.

\section{Method}

In this article we describe the Discrete Choice Experiment (DCE), a survey method borrowed from economics that allows us to quantify the value respondents place on the attributes of goods and services, and to explore whether and to what extent they are willing to trade-off less of one attribute for more of another.

\section{Conclusions}


To date, DCEs have been used to look at medical workforce issues but relatively little else in the field of medical education. However, many outstanding questions within medical education could be usefully addressed using DCEs. A better understanding is needed of which attributes have most influence on, for example, staff and/or student satisfaction, choice of university and choice of career, and to what extent stakeholders are prepared to trade-off between those attributes. Knowing this will allow us to tailor the way medical education is provided to better meet the needs of key stakeholders within the available resource.

\section{INTRODUCTION}

A previous article in the 'cross-cutting edge' series in this journal described the range of economic methods used in cost analyses that can be applied to medical education. ${ }^{1}$ Walsh et al described the application of different cost analyses methods to help define and value different forms of medical education, most commonly in monetary terms. We welcome the increasing focus on the economics of medical education, particularly in this time of increasing calls for accountability in health professional education. ${ }^{2}$ However, value is not just about money; value can also mean subjective worth, or what is important to an individual. Understanding value and relative value can help answer numerous questions in medical education and training. For example, what contributes most to student satisfaction with a particular rotation or course? What is the deciding factor in choosing a medical school or residency programme? What "packages" might be most effective in attracting doctors to work in remote and rural positions?

While there is an extensive literature examining what is important to patients in terms of delivery of care, ${ }^{3-7}$ looking at what is valued in education and medical education is relatively new (see later in this paper for examples). Yet knowing what is valued by applicants, students, trainees and colleagues is of increasing importance in the higher education and medical job market places. Medical schools, residency/training programmes and employers are under increasing pressure to provide a high quality, consumer-centred experience in a resource-constrained educational and 
occupational marketplace. Medical education and training are commodities, and when assessing the value of a commodity, it is important to consider the views of consumers. In other words, in order to develop a commodity that is workable (i.e. that meets the needs and preferences of users), providers and policy makers need to consider not only their own preferences (and constraints), but also those of the users.

As a first step in addressing this gap in medical education research, the current paper is a synopsis of theory and findings published predominantly in health economics which are relevant to the health professions education community. ${ }^{8}$ We focus on a quantitative research method known as discrete choice experiment (DCE) which is frequently used within a cost-benefit analysis framework. The aim of our paper is to summarise what DCEs are, what they involve, how they have been used previously, and to suggest ways in which they can be used to inform how different aspects of medical education and training might be optimised. Throughout this paper, we will use actual and hypothetical examples and case studies to illustrate the processes and possibilities of conducting DCE work within medical education.

\section{WHAT IS A DCE?}

DCE is a multi-dimensional stated preference (SP) method $^{9}$ used to elicit respondents' preferences for attributes of an item under investigation. SP methods are used to elicit an individual's preferences for 'alternatives' (whether goods, services, or courses of action) when actual behaviour cannot be observed. DCEs allow us to value individually or as a 'bundle', the component parts (attributes) of goods, services or interventions in monetary terms or alternative relevant measures, from an individual or societal perspective. ${ }^{10-12}$ Crucially, DCEs also enable us to determine the relative importance of those attributes and how people might trade between them.

DCE surveys originally evolved from conjoint analysis methods, developed in the 1970 s when they were predominantly used in the domains of market research and transport studies to understand consumer demand for goods and services. ${ }^{13}$ In conjoint analysis, participants are typically offered a 
predetermined set of potential products or services, and their responses (preferences) analysed to determine the implicit valuation of the individual elements of the product or service. Take for example buying a new car. The deciding factors might be: price, brand, hatchback, sun-roof or hybrid engine. How do those considering buying a new car trade between these factors?

The field evolved and emphasis shifted from conjoint analysis approaches, based on mathematical theory, to the DCE approach which is based on theories of choice behaviour. ${ }^{14}$ DCEs are underpinned by two key theories. The first of these, Lancaster's Characteristic's Theory of Value, is based on the idea that the value (or utility or satisfaction) that an individual associates with any item (good) "is derived from the characteristics (also known as attributes) that make up the good, rather than the good per $s e^{\prime \prime} .{ }^{15}$ The utility $(U)$ associated with an item is thus represented as a function of all attributes:

$$
U=U\left(X_{1}, X_{2} \ldots X_{k}\right)
$$

where $X$ represents the utility associated with each of the $k$ attributes of the item under investigation.

The second underpinning theory is Random Utility Theory (RUT). RUT posits that individuals make choices based on their personal preferences (observable factors), but that choices can also be influenced by random, unexplainable factors. ${ }^{16}$ Thus, for an alternative $j$ (i.e. a scenario comprising all attributes at specified levels) the utility function $(U)$ of an individual $(n)$ can be represented as:

$$
U_{n j}=V_{n j}+\varepsilon_{n j}
$$

where $V$ is the 'systematic' component of the function and $\varepsilon$ is a 'random' component. Further, the systematic component $(V)$ is a function of the attributes and levels, i.e. the observable components, of the item under investigation:

$$
V_{j n}=\mathrm{ASC}_{j}+\beta_{1} X_{n j 1}+\beta_{2} X_{n j 2} \ldots \beta_{K} X_{n j K}
$$


where ASC 'captures the mean effect of the unobserved factors in the error terms for each of the alternatives ${ }^{\prime 17}$ and $\beta^{\prime}$ s are the regression coefficients for each of the attributes, used to quantify strength of preference.

Consistent with their origins in consumer theory, DCEs operate under an assumption of utility maximising behaviour, i.e. that DCE respondents are 'rational agents' and will prefer the options that offer the greatest utility (or value or satisfaction) for least outlay. ${ }^{18}$

\section{WHY USE A DCE?}

You may think we are forever asking, and being asked, to state preferences. The most commonly used methods for eliciting preferences are ranking and rating scales, for example, by expressing how much you agree or disagree with a particular statement (e.g. 'this training was a good use of my time') on a numeric scale. ${ }^{19}$ Some forms of best-worse scaling, another technique of eliciting preferences increasingly used within health care, can be considered extensions of a ranking exercise. ${ }^{20}$ DCEs differ from traditional ranking and rating approaches in their assumptions, format and possibilities.

Typically, in a DCE survey, respondents are asked to answer a series of questions (choice sets) in which they must choose between two or more similar items (alternatives or scenarios) that are described in terms of a number of attributes, differing only in the levels allocated to those attributes (see Figure 1 for an example of a choice set). By systematically varying these levels, regression analyses can quantify not only the relative value respondents place on the individual attributes, but also the degree to which they are prepared to trade between them (see later for further explanation).

Once a good or service has been deconstructed into its component attributes in this way, we can reconstruct it again into specific scenarios of interest and compare directly the utility (or value or satisfaction) associated with these scenarios against one another. For example, attributes of a health 
service might be; distance to clinic, waiting time, consultation time, health care professional seen. A service delivered locally by a nurse with a waiting time of two months and consultation time of ten minutes, could be compared with the same nurse-led service in an out-of-town clinic with a waiting time of three months and a consultation time of 20 minutes.

\section{Trading between attributes}

The capability to quantify trading behaviour is a key advantage of DCEs. In an ideal world we would all like the best of everything (such a short waiting time and a longer appointment in the previous scenario); in reality, scarce resources mean we may have to compromise. Unlike ranking and rating scales, DCEs can inform providers' and policy makers' decisions about where, and to what degree, less favourable substitutions can be made and corresponding compensations applied. Where 'Cost' is included as an attribute, we can calculate how respondents value attributes in terms of monetary units and how much money would need to be offered to compensate for less preferred options (see below).

As an alternative to financial compensations, however, DCE findings can also be used to demonstrate how offering more of a 'less important' attribute (i.e. less preferred) might compensate for providing less of an 'important' one. For example, a 2015 study by Holte et al surveyed Norwegian final year medical students and interns to explore how factors such as practice size or opportunities to control working hours, might influence their choice between jobs in rural or urban areas. ${ }^{21}$ The authors concluded that the probability of young doctors choosing a rural job over an urban one could be improved by manipulating these non-pecuniary factors.

\section{Valuation on a common metric}

One way of evaluating a multi-component intervention would be to ask respondents to rate or rank the components in order of importance or preference. The problem with such methods is an inability to quantify the relative importance of components if those components are evaluated using 
non-quantifiable or dissimilar scales. For example, students might rank small tutorial groups more highly than weekly class assessments, but by how much do they prefer one over the other? Rating exercises often use satisfaction scales, but these can vary between applications (e.g. the number of points on the scale, the labels used etc.) making it difficult to compare across studies, and 'units' are difficult to quantify.

When one of a DCE's attributes is 'Cost' (or an alternative monetary measure, e.g. 'Salary' or 'Fees'), preferences can be measured using the common metric of monetary units. Willingness-to-pay (WTP) estimates can be calculated for marginal changes in attribute levels allowing direct comparisons both across attribute levels and between attributes. Other terms are sometimes used instead of willingness-to-pay, for example 'willingness-to-accept' or 'willingness-to-forgo', but calculations are identical. For example, in a 2012 study undertaken by Rockers et al (illustrated in Figure 1), researchers calculated respondents' willingness-to-forgo salary in exchange for better working conditions. ${ }^{22}$

The 'Cost' attribute can be described using defined sums of money in a relevant currency, or alternatively, can be represented as a proportion of a notional sum, e.g. average salary. For example, a 2016 DCE by Cleland et al concerned medical trainees' preferences for characteristics of a training post. Respondents were asked to choose between two hypothetical posts in which levels of the 'Potential earnings' attribute were set at $5 \%, 10 \%$ or $20 \%$ above average earnings ${ }^{23}$ Findings from this study revealed that trainees would accept a move from a position with 'good' working conditions (defined by "rotas, amount of on-call time, time off or staffing levels, etc.") to one with 'poor' conditions, if they were compensated with potential earnings of $49.8 \%$ above average earning potential (all other attributes being equal).

Where inclusion of a cost attribute is, for whatever reason, inappropriate, the relative value of attributes can be measured using an alternative continuous metric (e.g. time), or indeed, as a ratio of whatever natural units attributes are measured in. 
Alternative methods often used to value goods or services using the common metric of money, include contingent valuation (CV). In this case, respondents are asked to state their willingness-topay for an item under investigation. In contrast to DCE, which provides an indirect measure of WTP, $\mathrm{CV}$ methods require a direct response to a question such as: "How much would you be willing to pay for this item?" Design of a CV experiment comes with its own set of challenges. ${ }^{9}$ However, the main drawback when compared to DCE is that they value items as a whole, rather than as a set of component attributes. Thus, it is difficult to determine from a $\mathrm{CV}$ experiment how one might go about modifying a service or intervention to improve the utility it offers.

\section{Choices that mimic real life}

Choices made in a DCE are more similar to real-life situations than most other valuation techniques. Consumers are regularly faced with multi-attribute decisions in the market place, be it when buying food or clothing or when choosing a holiday or a car. Implicit in those decision-making situations is a weighing up of the pros and cons of the alternatives on offer. As described above, DCEs are multidimensional and allow trading between the component parts of the item under scrutiny. This similarity to real-life situations is likely to have a positive impact on the validity of the findings generated in DCEs.

\section{A testing ground}

The hypothetical nature of a DCE makes it a useful method for assessing goods, services or interventions that do not yet exist, meaning that this information cannot be observed through actual behaviour (revealed preferences), or where we can only observe a single net effect of the good/service/intervention, meaning that valuable information about the component parts is unobservable. Thus, proposals for new ways of providing e.g. medical education or alternative medical career paths can be evaluated in the first instance without 'real' (revealed preference) data that may not be feasible to collect, or could only be collected through costly pilots. For example, Robyn et al conducted a DCE amongst students and health workers in Cameroon to explore the 
impact of incentives on preferences for rural posts. ${ }^{24}$ Analysis of the preference data included estimating the impact on preferences of ten separate 'packages', each of which offered different incentives. Clearly, it would be unfeasible to test such a large number of packages in real life. Instead, the DCE provided information about hypothetical packages that policy makers and providers could use to decide which incentives were most likely to achieve the desired ends (improved recruitment and retention of health workers in rural areas) within available budgets.

\section{DCE DESIGN AND ANALYSIS}

\section{Attribute selection}

Crucial to the development of a DCE is the selection of attributes and levels. It is self-evident that when undertaking DCEs to inform policy or practice, attributes and their levels must be plausible and actionable; there would be little point in valuing items that are unrealistic or undeliverable, or with which respondents could not engage. This step in DCE design is important to ensure that participants can understand and engage with the experiment, and that the results are of practical use.

Best practice dictates that, as well as reviewing the relevant literature, qualitative methods are employed to explore which aspects of the item under investigation are important to stakeholders. ${ }^{25,}$

${ }^{26}$ Qualitative methods allow researchers to not only define the range of potential attributes, but also to achieve an in-depth understanding of the context in which the attributes exist, and the language commonly used by stakeholders to describe them. For example, in a study exploring medical students' preferences for characteristics of rural medical postings in Ghana, Kruk et al conducted seven focus groups with third and fifth year medical students to collect data for attribute development. ${ }^{27}$ Discussions covered students' experiences, perceived barriers and motivators to rural practice, as well as their career plans. To ensure that consideration was given to a wide range of perspectives, focus group participants were also asked to consider potential attributes extracted from a literature review and from discussions with practising and governmental physicians. 


\section{Contextualising the experiment}

It is important that respondents in any given DCE are all answering the same fundamental question.

This means not only that they answer the same choice sets, but also that the conditions under which choices are made are the same. As far as is possible, the researcher must try to cut down on 'background noise' and reduce unmeasured variation in respondents' decisions.

For example, in Uganda, in response to difficulties recruiting and retaining health workers in rural areas, Rockers et al undertook a DCE to analyse the preferences of medical, nursing, pharmacy and laboratory students for potential rural postings. ${ }^{22}$ Figure 1 shows an example from the online DCE sent to medical students in which we see that, prior to choosing their preferred posting, respondents are asked to imagine the scene:

Figure 1. Medical students' DCE choice question from Rockers et al, 2012. ${ }^{22}$

Imagine that you have just completed your medical school training and you have also COMPLETED YOUR INTERNSHIP AND BEEN CONFIRMED. You have decided NOT to go directly into specialty training. Rather, you have decided to begin working as a general practitioner. You are checking the newspaper for available job postings, and find that there are two postings available in government run health facilities. Both of the facilities in these postings are located in rural areas. Both facilities are equal distance from the nearest big town, and are equal distance from Kampala. Also, both of these facilities are in areas that are entirely safe from violent conflict. However, each of these two postings has different benefits, including: salary, housing, the quality of the facility, the length of time you are committed, preferences given for study placement after the commitment is over, and support from the district health officer.

Please imagine yourself in this situation and make a real decision as to which of these two postings you would prefer. Although we know that some government benefits to health workers have not been properly implemented in the past, please assume that you will receive the full benefits described for your posting. In making your choice, please read carefully the full list of benefits for each posting and do not imagine any additional features of these postings.

Please tell us which of these job postings you prefer.

Choose by clicking one of the buttons below:

\begin{tabular}{|l|l|l|}
\hline & Posting A & Posting B \\
\hline & $\begin{array}{l}\text { Basic (e.g. unreliable electricity, } \\
\text { equipment and drugs and supplies } \\
\text { not always available) }\end{array}$ & $\begin{array}{l}\text { Advanced (e.g. reliable electricity, } \\
\text { equipment and drugs and supplies } \\
\text { always available) }\end{array}$ \\
\hline Housing & Free basic housing provided & $\begin{array}{l}\text { Housing allowance provided, } \\
\text { enough to afford basic housing }\end{array}$ \\
\hline $\begin{array}{l}\text { Length of } \\
\text { commitment }\end{array}$ & $\begin{array}{l}\text { You are committed to this position } \\
\text { for 2 years }\end{array}$ & $\begin{array}{l}\text { You are committed to this position } \\
\text { for 5 years }\end{array}$ \\
\hline
\end{tabular}




\begin{tabular}{||l|l|l|}
\hline Study assistance & $\begin{array}{l}\text { The government will pay your full } \\
\text { tuition for a study program (e.g. } \\
\text { specialty training) after your } \\
\text { commitment is over }\end{array}$ & $\begin{array}{l}\text { The government will not provide any } \\
\text { financial assistance for a study } \\
\text { program after your commitment is } \\
\text { over }\end{array}$ \\
\hline Salary & $\begin{array}{l}\text { 700,000 USh per month } \\
1,000,000 \text { USh per month }\end{array}$ \\
\hline Management & $\begin{array}{l}\text { The district health officer in your } \\
\text { district is supportive and makes } \\
\text { work easier }\end{array}$ & $\begin{array}{l}\text { The district health officer in your } \\
\text { district is not supportive and makes } \\
\text { work more difficult }\end{array}$ \\
\hline \multicolumn{2}{|c|}{ O } \\
\hline
\end{tabular}

These additional instructions aim to ensure that respondents have a clear idea of the circumstances surrounding the choice (which may differ from the situation they find themselves in at present), thus minimising any variation in the interpretation of the choice situation.

\section{Generating the DCE design}

A full account of DCE design is beyond the scope of this article; such information is, however, readily available from existing literature. ${ }^{17,28}$ Briefly, once attributes and levels have been decided upon, statistical software such as $\mathrm{SAS}^{29}$ or Ngene ${ }^{30}$ is most commonly used to create and select a series of hypothetical scenarios (also known as alternatives or profiles), each of which presents the included attributes, set at different levels. This is illustrated in Figure 1 above, where respondents must choose from Posting A or Posting B. When these scenarios are combined in sets of two or more, the resulting 'choice sets' will represent a statistically efficient design, i.e. one that will collect sufficient information to allow preferences to be estimated with acceptable precision.

\section{Data collection}

In general, DCEs are embedded in surveys, and the principles of good survey design are as important in DCEs as any other survey. ${ }^{31,32}$ These include qualities such as ease of reading, clear instructions, absence of questions likely to lead to bias, appropriate response categories, logical ordering of questions etc. Survey mode should also be carefully selected. Increasingly, the internet is being used to administer surveys, including DCEs, for reasons that include lower research costs. Researchers must, however, be aware that using different modes (e.g. mail, internet, interviews) to collect data 
can lead to variations in representativeness, convergent validity and data quality. ${ }^{33,34}$ Choice of survey mode will depend on the research question and population of interest and findings should be interpreted with mode effects in mind.

\section{Analysis}

Analysis of DCEs has advanced since their first application in health care, and continues to evolve. Briefly, choice data are, in general, analysed using regression techniques. In early examples of DCE, the most frequently used regression analysis was conditional logit (also known as multinomial logit or $\mathrm{MNL}$ ), a technique similar to logistic regression. More recently, other models have been used to explore variability in preferences (i.e. how individual respondents differ in their preferences) using, for example, mixed logit and latent class logit models. ${ }^{35,36}$

\section{Limitations and Developments}

Collecting data from hypothetical scenarios in DCEs has drawn some criticism about their external validity and the possibility of hypothetical bias; how can we be sure that choices made under hypothetical circumstances reflect those that respondents will make in real life? Few studies have considered external validity of health-related DCEs; a recent systematic review and meta-analysis included eight such studies that had tested external validity by comparing predicted choices with those observed in real life. ${ }^{37}$ The authors found that DCEs had "moderate, but not exceptional, accuracy when predicting health-related choices"; pooled sensitivity and specificity estimates were 88\% (Cl 81-92\%) and 34\% ( $\mathrm{Cl} 23-46 \%)$ respectively. Their conclusions concur with those of Janssen et al (2017) who, while acknowledging that DCEs are a useful way of eliciting preferences, urge caution when interpreting findings in the light of this uncertainty about external validity. ${ }^{38}$

The inclusion of a Cost attribute, whilst extremely convenient from the researcher's point of view, can lead to problems; a common metric based on money is useful to calculate WTP and thus compare the magnitude of the values respondents place on attributes, but it does not necessarily 
follow that they would actually be willing to pay the estimated amounts. Caution, therefore, should be exercised when interpreting WTP estimates.

A further potential problem is that some respondents may object to the idea of paying for the item under investigation, which can lead to protest behaviour where respondents simply do not consider the other attributes and do not engage with the experiment. This can often happen in the case of health care in the UK, which is usually free at the point of delivery, but may not be an issue in other contexts where paying for health care is the norm. Additionally, WTP estimates can be affected by issues around ability to pay; respondents' choices may be influenced by how much they can afford, rather than how they value the attributes.

The role of heuristics, developed within cognitive psychology, ${ }^{39}$ and its implications for choices made within DCEs has also been considered within DCEs. ${ }^{40}$ An heuristic is an efficient rule that is followed to simplify a complex decision-making task. One such rule, attribute non-attendance (ANA), may lead certain attributes to be systematically excluded from decision-making. Research is also utilising eye-tracking techniques to consider the divergence between stated attendance of attributes and visual attendance. ${ }^{41}$ More recent research has investigated whether evidence of ANA within DCEs points to respondents simplifying the hypothetical task (with the associated implications for biases within preference estimation) or whether it reflects actual preferences. ${ }^{42}$ Eye-tracking is also being used to consider how the processing of the information on offer within the survey design (such as attribute order) might influence choices made. ${ }^{43}$

\section{EXAMPLES OF DCES FROM THE LITERATURE}

A small number of DCEs have been used to elicit preferences concerning educational issues and early career choices. Other published DCEs, indirectly linked to medical education, have elicited preferences for different aspects of jobs or careers in health-related professions.

\section{Educational preferences}


DCEs can be used to inform the content and format of medical education. Cunningham et al conducted a DCE to establish medical students' preferences for the way in which the MD program at McMasters University was organised. ${ }^{44}$ The aim was to engender student engagement with the educational programme, on the assumption that this would improve its effectiveness. Medical students were asked to choose between alternate MD programs; 15 attributes were used to describe the hypothetical programs including tutorial group size, the degree to which tutorials were web-enhanced, the role of tutors and the format of tutorial problems. The study concluded that "most students preferred a small group, web-supported, problem-based learning approach led by content experts who facilitated group process." Findings also suggested, however, that students would accept a less preferred program if financial savings were to be reinvested in, for example, web-enhanced tutorial processes.

Other studies exploring non-medical students' preferences for aspects of education have been undertaken, for example:

- Amongst undergraduate business students in Ireland, a DCE was used to explore relative preferences for various features of assignment systems, including form of the assignment (online/paper), relevance to exams and the nature of any feedback on the assignment. ${ }^{45}$

- Students at the London School of Hygiene and Tropical Medicine completed a DCE to measure preferences for different attributes of an educational institution, including staff, syllabus and fees. ${ }^{46}$

- Secondary school students in Ireland participated in a DCE that aimed to measure preferences for various characteristics of higher education institutes such as travel time from home, the reputation of the course being offered and fees. ${ }^{47}$

Attracting secondary school students from particular segments of society to study medicine was the subject of a DCE study by researchers in Japan. ${ }^{48}$ The rationale for this study was to explore the 
likelihood of attracting students from low- and middle-income families by offering scholarships to private medical schools.

DCEs have also been used to explore preferences for post-graduate medical education. Mandeville et al used a DCE to determine how, amongst other job characteristics, location of speciality training might affect junior Malawian doctors' decisions about whether or not to stay in the country. ${ }^{49}$ A DCE amongst Danish general practitioners compared characteristics of alternate continuous professional development (CPD) programmes..$^{50}$

\section{Career preferences and workforce planning}

Cleland et al conducted a DCE amongst doctors in training posts to establish which characteristics of their jobs they most valued (see above). ${ }^{23}$ The same DCE amongst final-year medical students revealed that the relative importance of the attributes was similar to that observed among trainee doctors; the most highly valued for both groups was 'working conditions'. ${ }^{51}$ The authors propose that the findings from these studies will be useful to health care organisations because the job attributes considered are those that they are likely to have some control over. Hence, training positions in less popular specialities or geographical areas could be made more attractive by manipulating the attributes under scrutiny.

However, the majority of DCE studies looking at workforce issues have been conducted in low- and middle-income economies whose territories include large areas that are remote and rural or subject to political instability. Many such countries in Africa, Asia, and Central or South America have well documented problems recruiting and retaining health professionals and health workers of all levels of experience. A substantial number of DCEs have been undertaken to try to find what might make jobs in these areas more attractive; Table 1 lists some examples.

Table 1: Some examples of DCEs investigating recruitment and/or retention of health care workers in remote and rural areas of low- and middle-income countries. 


\begin{tabular}{|c|c|c|c|}
\hline Study & Country & Participants & Aim \\
\hline $\begin{array}{l}\text { Kruk et al } \\
(2010)^{27}\end{array}$ & Ghana & $\begin{array}{l}\text { Final year medical } \\
\text { students }\end{array}$ & $\begin{array}{l}\text { to assess "how students' stated } \\
\text { preference for certain rural postings } \\
\text { was influenced by various job } \\
\text { attributes" }\end{array}$ \\
\hline $\begin{array}{l}\text { Hanson et al } \\
(2010)^{52}\end{array}$ & Ethiopia & Doctors and nurses & $\begin{array}{l}\text { "to better understand how health care } \\
\text { workers might be influenced to practice } \\
\text { in rural settings" }\end{array}$ \\
\hline $\begin{array}{l}\text { Vujicic et al } \\
(2011)^{53}\end{array}$ & Vietnam & Physicians & $\begin{array}{l}\text { "to explore the key factors that } \\
\text { determine physician motivation and job } \\
\text { satisfaction" }\end{array}$ \\
\hline $\begin{array}{l}\text { Rockers et al } \\
(2012)^{54}\end{array}$ & Uganda & $\begin{array}{l}\text { Students (medical, } \\
\text { nursing, pharmacy, } \\
\text { laboratory) }\end{array}$ & $\begin{array}{l}\text { "to better inform the selection of } \\
\text { appropriate recruitment and retention } \\
\text { interventions based on health worker } \\
\text { preferences" }\end{array}$ \\
\hline $\begin{array}{l}\text { Miranda et al } \\
(2012)^{55}\end{array}$ & Peru & Doctors & $\begin{array}{l}\text { "to investigate doctors' stated } \\
\text { preferences for rural jobs" }\end{array}$ \\
\hline $\begin{array}{l}\text { Rao et al } \\
(2013)^{56}\end{array}$ & India & $\begin{array}{l}\text { Final year medical/ } \\
\text { nursing students; in- } \\
\text { service doctors/nurses } \\
\text { serving at Primary } \\
\text { Health Centres }\end{array}$ & $\begin{array}{l}\text { to examine "job preferences of doctors } \\
\text { and nurses to inform what works in } \\
\text { terms of rural recruitment strategies" }\end{array}$ \\
\hline $\begin{array}{l}\text { McAuliffe et al } \\
(2016)^{57}\end{array}$ & $\begin{array}{l}\text { Malawi, } \\
\text { Mozambique, } \\
\text { Tanzania }\end{array}$ & Obstetric care workers & $\begin{array}{l}\text { "to examine the employment } \\
\text { preferences of obstetric care workers } \\
\text { across three east African countries" }\end{array}$ \\
\hline $\begin{array}{l}\text { Efendi et al } \\
(2016)^{58}\end{array}$ & Indonesia & $\begin{array}{l}\text { Students (medical, } \\
\text { nursing, midwifery) }\end{array}$ & $\begin{array}{l}\text { "to analyze the job preferences of } \\
\text { health students to develop effective } \\
\text { policies to improve the recruitment and } \\
\text { retention of health students in remote } \\
\text { areas" }\end{array}$ \\
\hline
\end{tabular}

DCE studies looking at preferences for health care jobs have additionally been undertaken in high-

income economies such as Australia, Denmark, Canada, the US and the UK. The aims of these studies vary but include exploring preferences for: jobs in remote and rural areas, ${ }^{59-61}$ jobs in primary care, ${ }^{62-64}$ jobs in secondary care ${ }^{65}$ and alternative payment systems. ${ }^{66}$

\section{CONCLUSION}

In summary, DCEs have been used frequently to look at medical workforce issues but relatively little else in the field of medical education. In the wider education literature, there are a few examples of DCEs being used to assess other preferences related to assessment systems and satisfaction with programme/course qualities. There seems to us to be a number of outstanding questions within medical education that could be usefully addressed using DCEs. For example, what components 
underpin student satisfaction with specific aspects of a course (e.g. longitudinal clerkships, remote and rural placements) as well as the course more generally (knowing this could inform curricular design)? If students value ten different aspects of feedback practice, which do they value most (knowing this could inform/focus staff training)? What do applicants value when selecting a medical school or residency, or medical job (what can a medical school influence, which factors are nonadjustable)? Exploring what applicants, students, residents and colleagues value, in order to understand what shapes their choices, will help those involved with planning and delivering education to meet consumers' needs and expectations. Going back to our earlier point, in an ideal world we would all like the best of everything, but life is not ideal. If we ask our consumers what they want using tools that do not enable us to identify what is most important to them, we are in danger of not meeting their needs.

Medical education research is currently a small field of research, and one that has drawn heavily on expertise, approaches and theories from other fields. This has enabled medical education research to move relatively rapidly from local evaluation and audit, to considering questions and problems more generally, in terms of how they may contribute to new knowledge. We believe that DCE methodology has the potential to address many outstanding questions in medical education and training, and to provide more refined information than some traditional approaches. Extending the use of the method in medical education may also facilitate working with stakeholders outside academia (e.g. providers and policy makers) as well as partnerships with expert colleagues from health economics. This transdisciplinary working may provide the potential to identify and create new opportunities and questions. ${ }^{67}$

For readers who desire a full account of DCE design along with accompanying practical guidance, we recommend "How to Conduct a Discrete Choice Experiment for Health Workforce Recruitment and Retention in Remote and Rural Areas: A User Guide with Case Studies" from the World Health 
Organisation. ${ }^{68}$ Additional reading is available from the ISPOR group (International Society for Pharmacoeconomics and Outcomes Research). ${ }^{69,70}$

\section{REFERENCES}

1. Walsh K, Levin H, Jaye P, Gazzard J. Cost analyses approaches in medical education: There are no simple solutions. Med Educ 2013;47(10):962-8.

2. Baron RB. Can we achieve public accountability for graduate medical education outcomes?. Acad Med 2013;88(9):1199-201.

3. Fawsitt CG, Bourke J, Greene RA, McElroy B, Krucien N, Murphy R, et al. What do women want? Valuing women's preferences and estimating demand for alternative models of maternity care using a discrete choice experiment. Health Policy 2017;121(11):1154-60.

4. Whitaker KL, Ghanouni A, Zhou Y, Lyratzopoulos G, Morris S. Patients' preferences for GP consultation for perceived cancer risk in primary care: A discrete choice experiment. Br J Gen Pract 2017;67(659):e388-95.

5. Murchie P, Norwood PF, Pietrucin-Materek M, Porteous T, Hannaford PC, Ryan M. Determining cancer survivors' preferences to inform new models of follow-up care. $\mathrm{Br} J$ Cancer 2016;115(12):1495-503.

6. Mankowski C, Ikenwilo D, Heidenreich S, Ryan M, Nazir J, Newman C, et al. Men's preferences for the treatment of lower urinary tract symptoms associated with benign prostatic hyperplasia: $\mathrm{A}$ discrete choice experiment. Patient Preference Adherence 2016;10:2407-17.

7. Porteous T, Ryan M, Bond C, Watson M, Watson V. Managing minor ailments; the public's preferences for attributes of community pharmacies. A discrete choice experiment. PLOS ONE $2016 ; 11(3)$. 
8. Eva KW. The cross-cutting edge: Striving for symbiosis between medical education research and related disciplines. Med Educ 2008;42(10):950-1.

9. Bridges JF. Stated preference methods in health care evaluation: an emerging methodological paradigm in health economics. Appl Health Econ Health Policy 2003;2(4):213-24.

10. Ryan M. Discrete choice experiments in health care. Bmj 2004;328:360.

11. De Bekker-Grob E, Ryan M, Gerard K. Discrete choice experiments in health economics: a review of the literature. Health Econ 2012;21:145-72.

12. Ryan M, Gerard K. Using discrete choice experiments to value health care programmes: current practice and future research reflections. Appl Health Econ Health Policy 2003;2(1):55-64.

13. Green P, Srinivasan S. Conjoint analysis in consumer research: Issues and outlook. J Consum Res $1978 ; 5(2): 103-23$

14. Louviere JJ, Flynn TN, Carson RT. Discrete Choice Experiments Are Not Conjoint Analysis. Journal of Choice Modelling 2010; 2010;3(3):57-72.

15. Lancaster KJ. A new approach to consumer theory. Journal of Political Economy 1966;74(2):13257.

16. McFadden D. Conditional logit analysis of qualitative choice behavior. In: Zarembka P, editor. Frontiers in Econometrics New York: Academic Press; 1974. p. 105-42.

17. Ryan M, Gerard K, Amaya-Amaya M. Using Discrete Choice Experiments to Value Health and Health Care. 1st ed. Dordrecht: Springer; 2008.

18. Mas-Colell A, Whinston M, Green J. Microeconomic Theory. New York: Oxford University Press; 1995. 
19. Ryan M, Scott D, Reeves C, Bate A, van Teijlingen E, Russell E, et al. Eliciting public preferences for healthcare: A systematic review of techniques. Health Technol Assess 2001; 03//;5(5).

20. Cheung KL, Wijnen BFM, Hollin IL, Janssen EM, Bridges JF, Evers SMAA, et al. Using Best-Worst Scaling to Investigate Preferences in Health Care. Pharmacoeconomics 2016;34(12):1195-209.

21. Holte JH, Kjaer T, Abelsen B, Olsen JA. The impact of pecuniary and non-pecuniary incentives for attracting young doctors to rural general practice. Soc Sci Med 2015;128:1-9.

22. Rockers PC, Jaskiewicz W, Wurts L, Kruk ME, Mgomella GS, Ntalazi F, et al. Preferences for working in rural clinics among trainee health professionals in Uganda: A discrete choice experiment. BMC Health Serv Res 2012;12(1).

23. Cleland J, Johnston $\mathrm{P}$, Watson V, Krucien N, Skåtun D. What do UK doctors in training value in a post? A discrete choice experiment. Med Educ 2016;50(2):189-202.

24. Robyn PJ, Shroff Z, Zang OR, Kingue S, Djienouassi S, Kouontchou C, et al. Addressing health workforce distribution concerns: A discrete choice experiment to develop rural retention strategies in Cameroon. Int J Health Policy Manag 2015;4(3):169-80.

25. Coast J, Al-Janabi H, Sutton EJ, Horrocks SA, Vosper AJ, Swancutt DR, et al. Using qualitative methods for attribute development for discrete choice experiments: Issues and recommendations. Health Econ 2012;21(6):730-41.

26. Louviere J, Hensher D, Swait J. Stated Choice Methods: Analysis and Application. Cambridge: Cambridge University Press; 2000.

27. Kruk ME, Johnson JC, Gyakobo M, Agyei-Baffour P, Asabir K, Kotha SR, et al. Rural practice preferences among medical students in Ghana: A discrete choice experiment. Bull WHO 2010;88(5):333-41. 
28. Lancsar E, Louviere J. Conducting discrete choice experiments to inform healthcare decision making: A user's guide. Pharmacoeconomics 2008;26(8):661-77.

29. SAS Institute Inc. SAS Software, Cary, NC, USA.

30. ChoiceMetrics. Ngene Software, Australia.

31. Dillman D. Internet, Mail and Mixed-mode Surveys. Third ed. New Jersey: Wiley; 2009.

32. Stopher P. Collecting, managing and assessing data using sample surveys. Cambridge University Press; 2012.

33. Determann D, Lambooij MS, Steyerberg EW, de Bekker-Grob EW, de Wit GA. Impact of Survey Administration Mode on the Results of a Health-Related Discrete Choice Experiment: Online and Paper Comparison. Value Health 2017;20(7):953-60.

34. Boyle KJ, Morrison M, MacDonald DH, Duncan R, Rose J. Investigating Internet and Mail Implementation of Stated-Preference Surveys While Controlling for Differences in Sample Frames. Environ Resour Econ 2016;64(3):401-19.

35. Hauber AB, González JM, Groothuis-Oudshoorn CGM, Prior T, Marshall DA, Cunningham C, et al. Statistical Methods for the Analysis of Discrete Choice Experiments: A Report of the ISPOR Conjoint Analysis Good Research Practices Task Force. Value Health 2016;19(4):300-15.

36. Train K. Discrete choice methods with simulation. 2nd ed.Cambridge University Press; 2009.

37. Quaife M, Terris-Prestholt F, Di Tanna GL, Vickerman P. How well do discrete choice experiments predict health choices? A systematic review and meta-analysis of external validity. Eur J Health Econ 2018;:1-14. 
38. Janssen EM, Marshall DA, Hauber AB, Bridges JFP. Improving the quality of discrete-choice experiments in health: how can we assess validity and reliability?. Expert Rev Pharmacoecon Outcomes Res 2017;17(6):531-42.

39. Kahneman D. Attention and Effort. Englewood Cliffs: Prentice-Hall; 1973.

40. Scarpa R, Gilbride TJ, Campbell D, Hensher DA. Modelling attribute non-attendance in choice experiments for rural landscape valuation. Eur Rev Agric Econ 2009;36(2):151-74.

41. Balcombe K, Fraser I, Mcsorley E. Visual Attention and Attribute Attendance in Multi-Attribute Choice Experiments. J Appl Econom 2015;30(3):447-67.

42. Heidenreich S, Watson V, Ryan M, Phimister E. Decision heuristic or preference? Attribute nonattendance in discrete choice problems. Health Econ 2018;27(1):157-71.

43. Ryan $\mathrm{M}$, Krucien $\mathrm{N}$, Hermens $\mathrm{F}$. The eyes have it: Using eye tracking to inform information processing strategies in multi-attributes choices. Health Econ 2018;27(4):709-21.

44. Cunningham CE, Deal K, Neville A, Rimas H, Lohfeld L. Modeling the problem-based learning preferences of McMaster University undergraduate medical students using a discrete choice conjoint experiment. Adv Health Sci Educ 2006;11(3):245-66.

45. Kennelly B, Flannery D, Considine J, Doherty E, Hynes S. Modelling the preferences of students for alternative assignment designs using the discrete choice experiment methodology. Pract Assess Res Eval 2014;19(16):1-13.

46. Sheppard P, Smith R. What students want: using a choice modelling approach to estimate student demand. J High Educ Policy Manage 2016;38(2):140-9. 
47. Walsh S, Flannery D, Cullinan J. Analysing the preferences of prospective students for higher education institution attributes. Educ Econ 2017;:1-18.

48. Goto R, Kakihara H. A discrete choice experiment studying students' preferences for scholarships to private medical schools in Japan. Human Resources for Health 2016;14(1).

49. Mandeville KL, Ulaya G, Lagarde M, Muula AS, Dzowela T, Hanson K. The use of specialty training to retain doctors in Malawi: A discrete choice experiment. Soc Sci Med 2016;169:109-18.

50. Kjaer NK, Halling A, Pedersen LB. General practitioners' preferences for future continuous professional development: Evidence from a Danish discrete choice experiment. Educ Prim Care 2015;26(1):4-10.

51. Cleland JA, Johnston P, Watson V, Krucien N, Skåtun D. What do UK medical students value most in their careers? A discrete choice experiment. Med Educ 2017;51(8):839-51.

52. Hanson K, Jack W. Incentives could induce ethiopian doctors and nurses to work in rural settings. Health Aff 2010;29(8):1452-60.

53. Vujicic M, Shengelia B, Alfano M, Thu HB. Physician shortages in rural Vietnam: Using a labor market approach to inform policy. Soc Sci Med 2011;73(7):2034-70.

54. Rockers PC, Jaskiewicz W, Kruk ME, Phathammavong O, Vangkonevilay $\mathrm{P}$, Paphassarang $\mathrm{C}$, et al. Differences in preferences for rural job postings between nursing students and practicing nurses: Evidence from a discrete choice experiment in Lao People's Democratic Republic. Hum Resour Health 2013;11(1).

55. Miranda JJ, Diez-Canseco F, Lema C, Lescano AG, Lagarde M, Blaauw D, et al. Stated Preferences of Doctors for Choosing a Job in Rural Areas of Peru: A Discrete Choice Experiment. PLOS ONE $2012 ; 7(12)$. 
56. Rao KD, Ryan M, Shroff Z, Vujicic M, Ramani S, Berman P. Rural clinician scarcity and job preferences of doctors and nurses in India: A Discrete Choice Experiment. PLOS ONE 2013;8(12).

57. McAuliffe E, Galligan M, Revill P, Kamwendo F, Sidat M, Masanja H, et al. Factors influencing job preferences of health workers providing obstetric care: Results from discrete choice experiments in Malawi, Mozambique and Tanzania. Globalization Health 2016;12(1).

58. Efendi F, Chen C-, Nursalam N, Andriyani NWF, Kurniati A, Nancarrow SA. How to attract health students to remote areas in Indonesia: a discrete choice experiment. Int J Health Plann Manage 2016;31(4):430-45.

59. Gallego G, Dew A, Lincoln M, Bundy A, Chedid RJ, Bulkeley K, et al. Should I stay or should I go? Exploring the job preferences of allied health professionals working with people with disability in rural Australia. Hum Resour Health 2015;13(1).

60. Scott A, Witt J, Humphreys J, Joyce C, Kalb G, Jeon S-, et al. Getting doctors into the bush: General practitioners' preferences for rural location. Soc Sci Med 2013;96:33-44.

61. Li J, Scott A, McGrail M, Humphreys J, Witt J. Retaining rural doctors: Doctors' preferences for rural medical workforce incentives. Soc Sci Med 2014;121:56-64.

62. Wordsworth S, Skåtun D, Scott A, French F. Preferences for general practice jobs: A survey of principals and sessional GPs. Br J Gen Pract 2004;54(507):740-6.

63. Pedersen LB, Gyrd-Hansen D. Preference for practice: A Danish study on young doctors' choice of general practice using a discrete choice experiment. Eur J Health Econ 2014;15(6):611-21.

64. Scott A. Eliciting GPs' preferences for pecuniary and non-pecuniary job characteristics. J Health Econ 2001;20(3):329-47. 
65. Ubach C, Scott A, French F, Awramenko M, Needham G. What do hospital consultants value about their jobs? A discrete choice experiment. Br Med J 2003;326(7404):1432-5.

66. Kessels R, Van Herck P, Dancet E, Annemans L, Sermeus W. How to reform western care payment systems according to physicians, policy makers, healthcare executives and researchers: A discrete choice experiment Health policy, reform, governance and law. BMC Health Serv Res 2015;15(1).

67. McMichael A. What makes transdisciplinarity succeed or fail? First Report. In: Somerville MA RD, editor. Transdisciplinarity: recreating integrated knowledge. Oxford, UK: EOLSS Publishers Ltd; 2000.

68. World Health Organisation, 2012. How to Conduct a Discrete Choice Experiment for Health Workforce Recruitment and Retention in Remote and Rural Areas: A User Guide with Case Studies. Available at: http://www.who.int/hrh/resources/dceguide/en/. Accessed June 2018.

69. Bridges JFP, Hauber AB, Marshall D, Lloyd A, Prosser LA, Regier DA, et al. Conjoint analysis applications in health - A checklist: A report of the ISPOR Good Research Practices for Conjoint Analysis Task Force. Value Health 2011;14(4):403-13.

70. Johnson FR, Lancsar E, Marshall D, Kilambi V, Mühlbacher A, Regier DA, et al. Constructing experimental designs for discrete-choice experiments: Report of the ISPOR conjoint analysis experimental design good research practices task force. Value Health 2013;16(1):3-13. 